\title{
NOTÍCIAS DE EDUCAÇÃO: \\ REPRESENTAÇÕES EM JORNAIS SOBRE A EDUCAÇÃO EM MATO GROSSO NA ERA VARGAS
}

$(1937-1945)^{*}$

Education news: newspaper representations on education in Mato Grosso in Era Vargas (1937-1945)

Noticias de educación: representaciones en diarios sobre la educación en Mato Grosso
en la Era Vargas (1937-1945)

Carlos Edinei de Oliveira ${ }^{1}$

\begin{abstract}
Resumo
O presente artigo apresenta e analisa algumas notícias sobre educação publicadas nos jornais em Mato Grosso, durante a Era Vargas, em específico no período do Estado Novo (1937 1945). Metodologicamente os jornais, produto cultural e mercadológico, existentes no Arquivo Público de Mato Grosso (APMT) foram mobilizados para a escrita da história. A imprensa desse período é marcada pela propaganda varguista, pela configuração de um Estado patriótico e nacionalista. Porém, os jornais, ao apresentarem notícias sobre a educação revelam a cultura escolar produzida em Mato Grosso em período também marcado pela censura. As notícias em geral remetem a educação formal, ou ações realizadas pelas escolas, como textos que servem como receituários de como educar os filhos e/ou críticas à educação que os pais têm dado a seus filhos. A imprensa escrita e as mensagens dos governadores mato-grossenses são as fontes privilegiadas desta pesquisa cuja escrita tem inspiração teórica na história cultural de Roger Chartier.
\end{abstract}

PALAVRAS-CHAVE: Imprensa escrita. Mensagem do governador. Cultura escolar.

\begin{abstract}
This article shows and analyzes some news about education publicized in paper in Mato Grosso, while Vargas was in particular period of Estado Novo (1937-1945). Methodologically the news, and cultural product and marketing, existing in Public Archive of Mato Grosso (APMT) was mobilized to explain the history. The press in this period is reserved by Varguista advertising, and configuration of a Patriotic and nationalist state. But, in the news, when it shows information about education reveals the scholar culture produced in Mato Grosso of the period marked by the censure. The general news refer to formal education or works realized in schools, like texts that served like prescriptions like to educated the children and / or reviews by parents education have afforded to their children. The written press and the message of Mato Grosso governors are the privileged in this research whose write with theoretical inspiration in the historical culture of Roger Chartier.
\end{abstract}

\footnotetext{
${ }^{1}$ Doutor em Educação e professor adjunto, da Universidade do Estado de Mato Grosso - UNEMAT, do Programa de Pós-Graduação - Mestrado Profissional em História - ProfHistória e do curso de Arquitetura e Urbanismo / Unemat - Campus de Barra do Bugres. E.mail. carlosedinei@unemat.br
} 
KEYWORDS: Written press. Message from governor. School culture.

\section{Resumen}

El presente artículo presenta y analiza algunas noticias sobre educación publicadas en los periódicos de Mato Grosso durante la era Vargas, en especifico en el periodo del Estado Nuevo (1937 - 1945). Metodológicamente los periódicos, producto cultural y mercadológico, existentes en el Archivo Público de Mato Grosso (APMT) fueron movilizados para la escritura de la historia. La prensa de ese período estaba marcada por la propaganda varguista, y por la configuración de un Estado patriótico y nacionalista. Sin embargo, los periódicos al presentar noticias sobre la educación, revelan la cultura escolar producida en Mato Grosso en un período también marcado por la censura. Las noticias en general remiten a la educación formal, o acciones realizadas por las escuelas, como textos que sirven de recetarios de cómo educar a los hijos y/o críticas a la educación que los padres han dado a sus hijos. La prensa escrita y los mensajes de los gobernadores matogrossenses son las fuentes privilegiadas de esta investigación cuya escritura tiene inspiración teórica en la historia cultural de Roger Chartier.

PALABRAS CLAVE: Prensa escrita. Mensaje de gobernador. Cultura escolar

\section{INTRODUÇÃO}

Em agosto de 1941 no Rio de Janeiro, Lenine do Campos Póvoas², escreveu um pequeno texto que foi publicado no dia 24 de agosto pelo jornal A Cruz, em Cuiabá, narrando parte do significado da visita do presidente Getúlio Vargas a Mato Grosso e em específico, a capital Cuiabá, entre os dias 06 e 08 de agosto de 1941.

Pela primeira vez, na sua história, recebeu Mato Grosso a visita dum Chefe da Nação.

Fato auspicioso, sem dúvida, - pois jamais Presidente algum curou desobrigar-se desse dever de conhecer, de visu, as necessidades nacionais - essa visita é um título a mais de benemerência do atual governo da República.

Administrador atilado, o Presidente Vargas tem visto, com rara clarividência, os magnos problemas nacionais, a cuja solução devotamente se entrega.

Refeito o Brasil daquele período de nervosismo e incerteza, criado pela ação dissolvente de ideologias vesgas, acha-se agora inteiramente dedicado, com segurança e optimismo, à tarefa gigantesca da sua reconstrução, fiel ao lema: "Ordem e Progresso".

E Mato Grosso não permanece à margem dessa atividade incomum, que anima todo o território brasileiro; sua importância política e econômica foi sobejamente compreendida.

As visitas ao nosso Estado de tantos ministros, e agora, do Presidente da República, valem como a prova eloquente de que fomos chamados a ocupar o lugar, que de direito nos cabe na evolução nacional.

Recepcionando o Presidente Vargas, com as demonstrações espontâneas e inequívocas da sua tradicional hospitalidade, reafirmou o povo mato-grossense

\footnotetext{
${ }^{2}$ Cuiabano (1921 - 2007) estudou Direito no Rio de Janeiro, foi Deputado Estadual, Vice-Governador do Estado, membro do Instituto Histórico e Geográfico de Mato Grosso e da Academia Mato-grossense de Letras, jornalista e foi professor titular do curso de Direito da Universidade Federal de Mato Grosso.
} 
confiança que deposita no grande Chefe do Brasil e na orientação criteriosa do seu governo (PÓVOAS, 1941, p.01).

A visita do Presidente Vargas, durante o Estado Novo, a época da interventoria de Julio Müller fortalecia o movimento de interiorização produtiva do Brasil. Sua estada em Cuiabá, a visita e a inauguração de várias obras oficiais trouxe à capital de Mato Grosso o movimento do ideal processo de modernização.

O movimento de tornar o interior do Brasil moderno e produtivo na Era Vargas está explícito no programa de integração econômica e territorial conhecido como "Marcha para Oeste" que segundo Barrozo (2008, p.19):

Entre os objetivos explícitos da Marcha para o Oeste podemos destacar a ocupação dos “espaços vazios” do Centro-Oeste e da Amazônia Meridional, a produção para o mercado nacional e o esvaziamento dos centros urbanos com maior densidade demográfica, localizados no litoral brasileiro.

A Marcha para o Oeste, tinha como proposta de integrar o espaço do "sertão", Mato Grosso, considerado pela imprensa e intelectuais da época, aos espaços em desenvolvimento do Brasil. Essa ação estava no movimento integrador nacionalista proposto por Vargas que ao longo dos oito anos de Estado Novo, “deu continuidade à reestruturação do Estado brasileiro, orientando-se cada vez mais para a intervenção estatal na vida nacional e para o nacionalismo econômico” (D`ARAUJO, 2011, p.33).

Neste período em Mato Grosso, houve uma reorganização do espaço mato-grossense. Esta reorganização, além de uma configuração em relação a mudança dos seus limites da fronteira física, com a criação do território de Ponta Porã (1943) e do território do Guaporé (1943), também se expressou com as mudanças relativas a reconfiguração espacial da cidade de Cuiabá, como a expansão urbana e a construção de novas obras públicas, apresentando sua arquitetura com uma diversidade de linguagem, assim como, a atração de novos migrantes para Mato Grosso, mobilizados pela política de integração nacional.

Nesta configuração, o objetivo deste texto é apresentar e analisar algumas representações sobre a educação em Mato Grosso, durante o Estado Novo brasileiro, por meio de algumas notícias publicadas em jornais de Mato Grosso.

A notícia é um texto bastante recorrente nos meios de comunicação, sendo um dos principais tipos de textos jornalísticos e que tem como objetivo apresentar uma informação sobre determinada ocorrência. Para Costalles apud Medina (1978, p.68) a notícia "é uma preciosa oportunidade de participar muito mais intensamente e extensamente na História”. 
As representações sobre a educação em Mato Grosso foram divulgadas pelos jornais A Cruz (Jornal Católico fundado por Frei Ambrosio D`Aydé, em 1910) ${ }^{3}$, Correio Matogrossense, Estado de Mato Grosso (fundado por Archimedes Pereira Lima), A Batalha (fundado por Lenine Campos Póvoas), O Alliancista, O Operário e Voz do Norte. Neste sentido, a imprensa foi mobilizada para a escrita da História.

Dentre os meios de comunicação da sociedade moderna, o jornal é um veículo fundamental, porém exige tratamento cuidadoso quanto à sua análise externa, pois deve ser considerado como um objeto cultural, mas é também mercadoria, é um produto da empresa capitalista (BITTENCOURT, 2004).

Deve-se considerar que a imprensa possui a sua historicidade articulada ao contexto social no qual está inserida e, ainda, que é parte ativa na sociedade e não apenas um depositário de acontecimentos. Como uma via de mão dupla, os jornais e as revistas representam identidades, mas também contribuem para a construção de outras (OLIVEIRA, 2016, p.18).

Portanto, ao utilizarmos o jornal como objeto de análise, devemos entendê-lo como um instrumento formador de opinião pública, com diferentes interesses, e que se relaciona com a estrutura política e com o poder.

A escolha de um jornal como objeto de estudo justifica-se por entender-se a imprensa fundamentalmente como instrumento de manipulação de interesses e de intervenção na vida social; nega-se, pois aqui, aquelas perspectivas que a tomam como mero "veículo de informação", transmissor imparcial e neutro dos acontecimentos, nível isolado da realidade político-social na qual se insere (CAPELATO; PRADO, apud LUCA, 2005, p.118).

Outro fato a ser considerado para a análise das representações dos jornais, cujas notícias apresentadas não são neutras e nem imparciais, é o problema da censura. Os periódicos verificados são do Estado Novo brasileiro, período que ocorreu repressão intensa, cerceamento de liberdades, valorização das elites, exclusão das massas e controle do Estado brasileiro pelo poder executivo (CAPELATO, 1998).

A propaganda varguista, a proposta do Estado patriótico e nacionalista, serão conteúdo das manchetes e dos diferentes textos dos jornais. As diversas imagens, sobretudo as utilizadas para destacar algumas ações produzidas nas escolas para consolidar a construção do civismo podem ser observadas, em especial, nas ilustrações que retratam os desfiles cívicos, uma teatralização da política com o objetivo de disciplinar a massa.

\footnotetext{
${ }^{3}$ Para análise deste periódico é importante ver a dissertação de mestrado de OLIVEIRA, Daniel Freitas de $O$ jornal A Cruz: imprensa católica e discurso ultramontano na Arquidiocese de Cuiabá (1910-1924). (Dissertação). 223f. Programa de Pós-Graduação em História. Dourados: UFGD, 2016.
} 
Os jornais, em suas folhas amareladas pelo tempo, guardadas no acervo do Arquivo Público do Estado de Mato Grosso (APMT) revelam a cultura escolar produzida nas escolas de Mato Grosso. As imagens apresentam espaços internos e externos, os textos das notícias em geral, apresentam um discurso de sucesso e benfeitorias produzidas durante a interventoria de Julio Müller e permitem aos historiadores a pensarem: "que o conhecimento que produzem não é mais que uma das modalidades da relação que as sociedades mantêm com o passado" (CHARTIER, 2009, p.21).

\section{Do que tratam as notícias}

Folheando os jornais do final dos anos de 1930 e da primeira metade dos anos 1940 do século XX, as propagandas de produtos e serviços podem causar um impacto muito significativo, percebe-se como a tecnologia do tempo presente, faz com que os efeitos apelativos das propagandas do passado, transforme-se em motivos quase anedóticos. São pitorescos os convites às senhoras para comprarem Sapatos Luis XV e ou mexicano. A motivação para que as pessoas pudessem se hospedar no Grande Hotel, destacando as qualidades de higiene e de boa cozinha, assim como, o incentivo para que todos fossem ao Cine Teatro assistirem "O filho de Tarzan", dentre outros chamados que incentivavam o consumo.

Sobre a educação, as notícias são apresentadas em forma de texto escrito e também de imagens. É muito presente nos jornais, notícias que remetem a educação formal, em geral escolas, ou ações realizadas pelas escolas, como textos que servem como receituários de como educar os filhos e ou críticas a educação que os pais têm dado a seus filhos.

No período entre 9 de março de 1937 à 13 de setembro de 1937, o interventor do Estado de Mato Grosso foi o Cap. Manoel Ary da Silva Pires. No momento de sua posse, Ary Pires, proferiu a seguinte mensagem à Assembleia Legislativa do Estado de Mato Grosso, apresentado uma visão dos aspectos educacionais que Julio Strübing Müller ${ }^{4}$ enfrentaria no decorrer de 1937.

\footnotetext{
${ }^{4}$ Em 13 de setembro de 1937, com a morte de Correia da Costa, Julio Müller foi eleito governador pela Assembleia Legislativa, com mandato até 15 de agosto de 1939. Tomou posse no dia 4 de outubro, tendo administrado o estado como governador constitucional por pouco mais de um mês, já que a implantação do Estado Novo no dia 10 de novembro suspendeu todos os mandatos eletivos do país. Entretanto, no dia 24 de novembro foi reconduzido ao governo de Mato Grosso, desta vez como interventor federal no estado (FGV/CPDOC/
} 
Desprotegidas, abandonadas por completa dos sistemas educacionais que o Estado lhes deveria proporcionar, com a criação do serviço de proteção á infância nas escolas, mal alimentadas sem noções dos mais rudimentares preceitos de higiene, a criança das nossas escolas, na sua maioria são pálidas, retardadas no crescimento, sujeitas a contaminação das endemias que anualmente assolam, e que não sabem evitar por ignorância.

Outros fatores de ordem mesologica, concorrem singularmente para esse estado depreciativo. Neste tocante urge a ação conjunta do professor e do médico nas escolas; um corrigindo os caracteres incipientes, alimentando a alma, a moral da infância, o outro avigorando-lhe o cérebro, concorrendo assim para a maior das obras humanas a salvação da crença, o saneamento da raça, a elevação da sociedade, a grandeza da pátria (PIRES, 1937, p.18).

Às vésperas do Estado Novo, quando Julio Müller tomou posse, ainda como governador do Estado de Mato Grosso, o jornal Alliancista, no dia 10 de outubro de 1937 publicou o discurso do governador, uma breve resposta ao discurso de Ary Pires. "A instrução pública, principalmente a primária, merecerá do meu Governo o maior cuidado e todo o amparo, doptando-a de melhoramentos materiais como creando escolas eficientes providas de professorado competente" (MÜLLER, 1937, p.3).

No discurso do interventor Cap. Manoel Ary da Silva Pires há uma parte da mensagem que destaca o Liceu Cuiabano. "Quanto ao Liceu Cuiabano, tive oportunidade de visitar este estabelecimento de ensino secundário, havendo observado a grande necessidade de melhoramentos materiais que acuse o edifício em que funciona" (PIRES, 1937, p.15). Nesta época o Liceu Cuiabano, funcionava no Palácio da Instrução, mesmo local, em que funcionava a escola Normal e a Escola Modelo de Cuiabá.

A Escola Modelo "Barão de Melgaço" foi uma instituição de ensino primário que serviu de "oficina pedagógica" para os alunos da Escola Normal, além de ser o espelho para as demais escolas primárias do Estado. Algumas normas administrativas e pedagógicas foram criadas a fim de regulamentar essa instituição de ensino, que representava a inovação pedagógica e tinha como dupla função: lecionar as primeiras letras aos alunos do ensino primário e destinar-se a prática pedagógica obrigatória dos alunos do $2^{\circ} \mathrm{e} 3^{\circ}$ anos normais. De acordo com o Regulamento da Escola Normal, decreto $\mathrm{n}^{\circ} 353$, cap. 12, art. 131, ficou estabelecido que anexo a ela haveria um Grupo Escolar. Conforme diz o parágrafo único: "O Grupo Escolar será denominado "Escola Modelo anexa" e será destinado a preparar preliminarmente as crianças de ambos os sexos e a prática dos alunos do $3^{\circ}$ ano e do $4^{\circ}$ ano do curso Normal, servindo de typo para todos os grupos escolares do Estado". Oportunizava se aos normalistas que colocassem em prática o que aprendiam na teoria. Estudavam no período da manhã, na Escola Normal, e, à tarde, lecionavam nas turmas de ensino primário, na Escola Modelo (REIS, 2006, p.48).

Porém, na leitura do Jornal o Estado de Mato Grosso, de 04 de outubro de 1939, deparamos com uma longa manchete: “A Instrução sob o governo Julio Müller - O Liceu Cuiabano, completamente remodelado readquire o seu antigo prestígio de modelar 
estabelecimento de ensino secundário - As notáveis instalações de que vem o Governo do Estado de dotar o tradicional estabelecimento".

Junto a manchete aparecem seis ilustrações na mesma página, que trazem as seguintes legendas "A nova sede do Liceu Cuiabano", "O moderno gabinete de física recentemente adquirido pelo governo Julio Müller para o estabelecimento oficial", "Museu de História Natural", “Uma secção dos higiênicos bebedouros de d'água gelada do Liceu”, "Laboratório de Química - Uma aula de Química do Prof. Dr. Antonio Felizola" e "2º ano ginasial Provas parciais - Vê-se ao fundo o Inspetor dr. Fenelon Müller”.

A manchete e as imagens apresentam ao leitor as novas instalações do Liceu Cuiabano, destaque para a reforma da fachada do prédio do antigo Palácio da Instrução, e a aquisição de infraestrutura básica e espaços específicos para o desenvolvimento das aulas. Pode-se verificar essas ações pelo relatório do interventor Julio Müller enviado ao presidente Vargas em agosto de 1940, em que destaca:

Outro problema da alta relevância que se antolhou ao meu governo é a dotação das casas de ensino no Estado do necessário mobiliário escolar.

Dando efeito a este, minha constante preocupação, venho aparelhando os estabelecimentos de ensino público do material escolar imprescindível de que careciam.

Durante o ano de 1938, adquiriram-se 600 carteiras brasileiras, tipo B-10, e 200 poltronas destinadas estas ao Liceu Cuiabano (MÜLLER, 1940, p.12)

No mesmo relatório, o interventor Julio Müller, continua apresentando alguns dados estruturais e pedagógicos do Liceu Cuiabano:

Dos referidos, só o Liceu Cuiabano, na capital, o qual conta 60 anos de existência, está no regime de inspeção permanente, achando-se os dois outros sob o regime de inspeção prévia.

[...].

Foi consideravelmente aumentado o material dos Gabinetes de Física, Química, História Natural, Geografia, Desenho e Educação Física, no que o Estado despendeu 24:536\$050.

Foi instalado, com todos os requisitos, o Gabinete de Biometria.

O Curso Fundamental do Liceu Cuiabano contou com 427 matrículas, e o Curso Complementar, com 19, sendo 14 na seção de medicina, farmácia e odontologia e 5 na do jurídico (MÜLLER, 1940, p.13).

Em Mato Grosso, durante o Estado Novo, houve um avanço em relação aos períodos anteriores sobre a formação de professores para o ensino primário. Em especial na capital do Estado, o que pode ser observado no relatório recebido por Vargas, do interventor em 1940.

Funcionou, também, junto ao Liceu Cuiabano o Curso Especializado de professores, com 3 alunos, e a seção Normal (remanescente da antiga Escola Normal) com 226 alunos.

[...] 
Anexo ao Liceu Cuiabano, funcionou o Curso de Especialização de Professores Primários, em dois anos seriados, criado, como já ficou dito acima, em substituição à antiga Escola Normal.

Visou, com isso, o governo dar aos professores primários uma ilustração maior e perfeita, exigindo dos mesmos além do curso ginasial completo, mais dois anos de especialização.

A penúltima turma de professores primários, formada sob a vigência do antigo regulamento, deu ao Estado, em 1939, mais de 100 normalistas (MÜLLER, 1940, p.13).

O Liceu Cuiabano, volta a ser manchete dos jornais em Cuiabá em 10 de novembro de 1944, com o nome de Colégio Estadual de Mato Grosso. As manchetes dizem respeito a inauguração do colégio. Esta edificação compôs o projeto das 14 "obras oficiais" realizadas durante o Estado Novo brasileiro em Cuiabá.

O monumental edifício do Colégio Estadual de Mato Grosso, que hoje será inaugurado solenemente, é uma verdadeira obra prima de bom gosto arquitetônico e, ainda, uma perfeição no que concerne às experiências da moderna pedagogia. Projetado por arquitetos especializados da divisão de construções de estabelecimentos educandários da firma Coimbra Bueno, o grande Colégio será um dos mais completos do Brasil. Construído de acordo com todas as exigências do Ministério da Educação, compreende o Colégio Estadual, cuja monumental expectativa se vê na gravura, um edifício principal, de dois pavimentos, com uma área construída de $3.732 .000 \mathrm{~ms}^{2}$ " "um ginassium”, com uma área de $840000 \mathrm{~ms}^{2}$; um estádio, compreendendo arquibancadas, pista de atletismo, campo de futebol, etc; e urbanização da Praça Marechal Mallet. Contém o edifício: 10 salas de aulas comuns; uma sala de aula de geografia; um conjunto de salas de aula de física e química; um conjunto idêntico para aulas de história natural; biblioteca; amplo anfiteatro com capacidade para 500 alunos; gabinete médico; "hall" nobre (COLÉGIO ESTADUAL ..., 1944, p.01).

Com a construção destas obras, que tiveram início em 1939, o governo de Vargas consolidava Cuiabá como capital do Estado de Mato, pois essa tinha uma importância geopolítica nos planos de ocupação produtiva do interior brasileiro e o estado convertia-se em palco de um programa de integração econômica do território nacional, a Marcha para o Oeste.

O conjunto arquitetônico produzido em Cuiabá, durante o Estado Novo é revelador de considerados aspectos em relação a vida econômica, social, cultural e a expansão urbana de Cuiabá, resultado da edificação de prédios públicos e do poder da Interventoria de Júlio Müller.

As obras foram realizadas para atender diversas áreas como justiça (Palácio da Justiça), educação (Colégio Estadual), administração (Secretaria Geral), infraestrutura urbana (Estação de tratamento de água, a ponte sobre o rio Cuiabá, agência dos Correios e Telégrafos), cultura (Cine Teatro Cuiabá, Clube Feminino), saúde (Usina de Pasteurização do leite), residência (Residência dos Governadores, Palácio Episcopal), hotelaria (Grande Hotel), 
forças armadas (16º Batalhão de Caçadores). Em agosto de 1941, Getúlio Vargas visita e inaugura uma parte dessas obras.

As denominadas “obras oficiais” dentre elas o Colégio Estadual de Mato Grosso, atual Liceu Cuiabano "Maria de Arruda Müller", foram construídas pela Construtora Coimbra Bueno e Cia. Ltda, que em 1934 já havia assumido a execução do plano urbanístico de Goiânia. O representante dessa construtora em Mato Grosso foi o engenheiro carioca Cássio Veiga de Sá, que chegou em Mato Grosso em novembro de 1938.

O Colégio Estadual de Mato Grosso foi edificado na recém-criada Avenida Presidente Vargas, que segundo Castor (2013, p.189) "Essa via arborizada converteu-se num mostruário das obras oficiais que surpreenderiam a paisagem cuiabana dali em diante, incluindo sua própria pavimentação em concreto. Foi a primeira avenida a romper com os tradicionais paralelepípedos que calçavam as ruas centrais da cidade.

A história do Colégio Estadual é assim narrada, em 1994, por sua patrona Maria de Arruda Müller, mulher do então interventor do Estado de Mato Grosso Julio Müller que escreve:

Agora, chega a minha vez: já na senectude, procurarei memorizar a segunda década deste século, já avançado para o fim...

Em 1910 começou a funcionar a Escola Normal no velho prédio à rua Galdino Pimentel, sob a orientação do professor Leovegildo de Mello, enquanto se erguia o Edifício do Palácio da Instrução.

O Liceu Cuiabano funcionava então, num casarão de esquina no início da Praça da República. Essa casa de velha estrutura cuiabana, pertencente outrora a Tte. Coronel Manoel Alves Ribeiro, irmão ou primo do Barão de Poconé.

Hoje, no lugar, foi erguido o Prédio dos Correios e Telégrafos.

Terminada a construção do Palácio da Instrução no local onde funcionou o $8^{\circ}$ Batalhão de Infantaria do Exército Nacional, a Escola Normal e o Liceu passaram a sediar ali; na ala direita o Liceu e na esquerda a Escola Normal, no andar superior. No térreo funcionaram as alas feminina, e masculina da Escola Modelo "Barão de Melgaço" (MÜLLER, 1994, p,26).

Maria de Arruda Müller em suas memórias sobre o Liceu Cuiabano, enfatiza o papel das mulheres na educação secundária e da co-educação presente na instituição de ensino:

Em 1910, o Liceu já havia bacharelado duas jovens: Josefina Poyarte e Maria Dimpina Lobo. Outras figuras femininas entre elas, Maria Venesa, eram alunas das séries mais elevadas quando nos matriculamos; éramos duas filhas de comerciantes e político Avelino de Siqueira, Maria Lacerda e eu, éramos nessa época quatros jovens no meio de um bando irreverente de rapazes muitos vindos do sul do Estado (MÜLLER, 1994, p,27). 
Porém, a memorialista continua em sua narrativa destacando que a partir do ano de 1944, “o velho estabelecimento básico em ciências e letras passou a ter sede definitiva, com o nome de Colégio Estadual, com o propósito de tirar-lhe o feitio regional abrangendo agora o domínio mais vasto, em todo o imenso Estado, o Governo Interventorial deu-lhe esse nome" (MÜLLER, 1994, p,27).

O Colégio Estadual teve inúmeras vezes seu regulamento alterado, atendendo as reformas nacionais e estaduais de ensino atendendo diversas gerações de mato-grossenses. $\mathrm{O}$ nome Liceu Cuiabano, foi restabelecido pelo Decreto n 1750, de 13 de março 1979, no centenário de sua criação, pelo governador Cássio Leite de Barros e em 1999, seu nome foi alterado, pelo decreto 2.812 de 11 de dezembro de 1998, para Escola Estadual de I e II graus Liceu Cuiabano "Maria de Arruda Müller" e depois O título ficou definitivo em 11 de outubro de 2000, pelo decreto ${ }^{\circ}$ 1826, passando a denominar Escola Estadual Liceu Cuiabano "Maria de Arruda Muller".

[...] a escola ocupa todo um quarteirão em frente à Praça General Mallet, na zona oeste da cidade. A grandeza e requinte da obra, a mais cara entre as 14 obras oficiais, refletem a importância concedida à arquitetura no programa educacional instituído pelo Estado Novo. [...] A planta em formato de "E" não pode ser apreciada independentemente das características do amplo terreno retangular que ocupa e delimita. Rompendo a simetria da planta, a ala que acompanha a lateral do terreno é mais comprida do que a do extremo oposto, o que contribui para resguardar o pátio formado no interior da quadra. As salas de aula dessa ala estão protegidas do ruído e da incidência do sol poente, pois o corredor que lhes dá acesso está voltado para o lado da rua.

O monumental pórtico central já não representa é o único ponto de acesso, pois há entradas para públicos específicos nos dois extremos da fachada, devidamente assinaladas e protegidas por varanda. Uma da direita é reservada aos professores e conduz diretamente à sala de reuniões dos mesmos e ambientes afins, a esquerda dá acesso à secretaria e demais salas administrativas, alinhadas na outra metade do bloco frontal. Mais baixos, esses setores frontais suavizam o impacto urbano do edifício, dando uma escala humana ao espaço da praça em frente. O efeito é reforçado, inclusive, pelo pórtico que antecede o saguão central de pé-direito duplo, valorizado por majestosa escadaria de dois lances. É por onde se sobe ao foyer do teatro, cujo corpo medeia os dois pátios simétricos de recreação nos fundos do colégio (CASTOR, 2013, p.193).

Edificações, como o Liceu Cuiabano, são reveladoras de saberes e técnicas construtivas de um determinado tempo, de ensinamentos, simbologias, relações sociais e de trabalho. Apropriar-se das representações dessas "obras oficiais" é oportunizar uma aproximação do presente com o pretérito, é possibilitar a compreensão e o significado da História de Mato Grosso e seus desdobramentos, produzidos na Era Vargas. 
Para além da arquitetura e de seus aspectos estruturais, algumas práticas escolares do Liceu Cuiabano são representadas nos jornais, como exemplo, os desfiles cívicos realizados pelo seu corpo discente. O jornal O Estado de Mato Grosso, de 07 de agosto de 1941 trouxe em uma das manchetes: "O impressionante desfile escolar de ontem em homenagem ao Presidente da República”. A notícia refere-se ao primeiro dia de visita de Getúlio Vargas a Cuiabá. Neste dia, os alunos e alunas do Liceu Cuiabano, apresentaram-se desfilando civicamente para o presidente.

Se as nossas forças armadas, Exército, Polícia e tiros de Guerra, brilharam, na magnifica parada de ontem, que tanto impressionou o Sr. Presidente da República, os nossos colégios, de seu turno, arrancaram pelo garbo com que apresentaram, os aplausos da multidão. E a prova do elan da nossa juventude é o detalhe que apresentamos na gravura da grande parada. Aparece aí a secção feminina do Liceu Cuiabano (O Impressionante..., 1941, p.1).

Outros momentos de desfiles cívicos são apresentados pelo periódico, acerca da presença de Vargas em Cuiabá:

O desfile constituiu sem favor, um acontecimento inédito da vida de Cuiabá, tal foi a sua majestade, a sua grandeza, a profunda compenetração de todo um povo que se descobre diante de um Chefe, que conta com o apoio integral de uma Pátria, a gratidão acendrada de um povo, o afeto de todas as nações de um continente e a admiração respeitosa de todos os povos (ARREBATADOR ..., 1941, p.01).

É importante considerar que estas festas cívicas, são marcas das encenações espetaculares e representações simbólicas do estadonovismo getulista, e pode ser considerado como um dos elementos constitutivos do denominado nacionalismo sadio, como ele mesmo afirma:

[...] não se cogitará apenas de alfabetizar o maior número de pessoas, mas, também, de difundir princípios uniformes de disciplina cívica e moral, de sorte a transformar a escola primária em fator eficiente na formação do caráter das novas gerações, imprimindo-lhes rumos de nacionalismo sadio (Getúlio Vargas apud Horta, 1994,173).

E também sobre a falta de escolas para que esse nacionalismo fosse realizado Alcides Gentil em 1939, expõe as ideias de Vargas:

A massa de analfabetos que possuímos, peso morto para o progresso da nação, tanto no que concerne ao nosso aparelhamento institucional, como no que toca ao desenvolvimento das nossas atividades produtoras, é mácula que nos deve envergonhar; cumpre aliás, confessá-la, não para recriminar inutilmente, mas para nos convencermos de que o ensino é matéria de salvação pública (Getúlio Vargas apud GENTIL, 1939, p.125). 
Neste sentido, o interventor Julio Müller, em continuidade ao exercício patriótico do Estado Novo, criou pelo Decreto n ${ }^{\circ} 53$ de 18 de abril de 1941 cem escolas rurais no Estado de Mato Grosso, 28 delas, uma em cada município, recebeu o nome de Escola “Getúlio Vargas". A notícia foi amplamente divulgada pelos jornais de Mato Grosso.

O jornal o Estado de Mato Grosso, no dia 19 de abril de 1941, apresentou aos seus leitores a seguinte manchete: "Em comemoração ao natalício do Presidente Vargas o governo do Estado baixou decreto criando cem escolas rurais no Estado".

No dia do aniversário do "Reconstrutor do Brasil", como afirmava o jornal O Estado de Mato Grosso, o interventor levou para o universo rural a possibilidade de estrutura física para escolarização, apenas no papel, porém não aparece no mesmo movimento uma política de formação de professores rurais para atender a demanda, e o periódico não apresenta nenhum dado sobre a questão, a criação por decreto já seria decisivo para a efetiva escolarização.

O exmo Sr. Interventor Julio Müller assinou ante-ontem um dos mais sábios e mais importantes decretos do seu governo: o decreto $\mathrm{n}^{\mathrm{0}} 53$, criando cem escolas no Estado. Antigo professor, conhecendo a fundo, os problemas de educação, com os quais se familiarizou durante os longos anos em que exerceu o magistério, ninguém mais que s. excia em condições de avaliar as necessidades do nosso ensino para supri-las, no momento oportuno, com um ato de tão elevado patriotismo, destinado à mais funda repercussão em todo o país.

O Decreto do Interventor Julio Müller, baixado justamente às vésperas de 19 de abril, em homenagem ao Chefe da Nação, cujo natalício hoje comemora, é digno de ser imitado, pelos demais governantes estaduais e, se for, o problema educacional brasileiro, na opinião de Miguel Couto o maior problema nacional, está em parte resolvido (CEM ESCOLAS..., 1941, p.02).

$\mathrm{O}$ ato do interventor Julio Müller, criando escolas, foi em atendimento a uma campanha do governo federal denominada Cruzada Nacional de Educação. Em quase todos os estados do Brasil escolas forma criadas em homenagem ao aniversário do Presidente Vargas, porém suas instalações e a escolha do professor para ocupá-las, aquelas que tiveram funcionamento na prática dependeu da política educacional de cada interventoria.

\section{CONSIDERAÇÕES FINAIS}

Muitas são as notícias que os jornais produziram sobre a sociedade e suas práticas durante o Estado Novo em Mato Grosso. Muitas indagações em relação: quem? onde? o que? como? quando? e por quê? podem ser realizadas aos periódicos, pois à História se interessa tanto pelo acontecimento, como por suas conexões. 
Estão presentes nas notícias deste período, e espera-se um trabalho denso do historiador, e do historiador da educação uma diversidade de temáticas. Os arquivos estão repletos de notícias para serem relidas e analisadas, os jornais precisam ser revisitados. Nas leituras dos jornais compreende-se a parcialidade dos seus agentes e este exercício permite aos fazedores de história contribuir para uma sociedade que possa ler o mundo com maior autonomia.

\section{REFERÊNCIAS}

ARQUIVO PÚBLICO DO ESTADO DE MATO GROSSO. APMT - LIVRO 71, p 14 - 23 e 45. Mensagem apresentada a Assembléia Legislativa lida na abertura da $3^{\mathrm{a}}$ sessão ordinária da sua $1^{a}$ legislatura, pelo Interventor Federal do Estado de Mato Grosso - Cap. Manoel Ary da Silva Pires. Cuiabá, 13 de junho de 1937.

ARREBATADOR espetáculo de inenarrável júbilo cívico, a chegada do Presidente Getúlio Vargas nesta Capital. In.: O Estado de Mato Grosso. Cuiabá, n. 534. 06 de ago, 1941. p.01.

CASTOR, Ricardo Silveira. Arquitetura moderna em Mato Grosso: diálogos, contrastes e conflitos. São Paulo, 2013. Tese (Doutorado - Área de Concentração: História e Fundamentos da Arquitetura e do Urbanismo) - FAUUSP.

CEM ESCOLAS. O Estado de Mato Grosso. Cuiabá, Ano II, n. 460. 19 de abr., 1941. p.02. CHARTIER, Roger. A história ou a leitura do tempo. Belo Horizonte: Autêntica, 2009. COLÉGIO ESTADUAL DE MATO GROSSO. O Estado de Mato Grosso. Cuiabá, n. 1.286. 09 de nov. 1944. p.02.

D`ARAUJO, Maria Celina. Getúlio Vargas, 1883-1954. Brasília: Câmara dos Deputados, Edições Câmara, 2011. 793 p. - (Série perfis parlamentares; n. 62).

HORTA, José Sivério Baía. O hino, o sermão e a ordem do dia: a educação no Brasil (19301945). Rio de Janeiro: Editora UFRJ, 1994.

JULIO MÜLLER. Verbete. FGV/CPDOC. Disponível em: <http://www.fgv.br/cpdoc/acervo/dicionarios/verbete-biografico/julio-strubing-muller>. Acesso em: <14 nov. 2017〉.

LACERDA, Leila Borges de. Patrimônio cultural de Cuiabá: preservação e história. Aguapé, 2004.

MEDINA, Cremilda. Notícia um produto à venda: jornalismo na sociedade urbana e industrial. São Paulo: Summus Editorial, 1978.

MÜLLER, JULIO. Relatório apresentado ao Exmo. Sr. Dr. Getúlio Vargas do Interventor Federal do Estado de Mato Grosso. APMT - Relatórios da Presidência do Estado de Mato Grosso - Livro 72. Cuiabá, agosto de 1940.

MÜLLER, JULIO. A instrução pública. In.: Alliancista, p.01, 10 out. 1937.

MÜLLER, Maria de Arruda. O Liceu Cuiabano: comemoração do Centenário de sua instalação. In: MÜLLER, Maria de Arruda; RODRIGUES, Dunga Rodrigues. Cuiabá ao longo de 100 anos. Cuiabá: Eletrônica Selma Carvalho, 1994. 
O IMPRESSIONANTE desfile escolar de ontem em homenagem ao Presidente da República. O Estado de Mato Grosso. Cuiabá, n. 535, 07 de ago, 1941. p.01.

OLIVEIRA, Daniel Freitas de. O jornal A Cruz: imprensa católica e discurso ultramontano na Arquidiocese de Cuiabá (1910-1924). 223f. (Dissertação) Mestrado em História. Programa de Pós-Graduação em História. Dourados: UFGD, 2016.

PÓVOAS, Lenine do Campos. A visita do presidente Vargas. A Cruz - Órgão da Liga do Bom Jesus, p.01. 24 ago. 1941.

REIS, Rosinete Maria Reis. A implantação dos grupos escolares em Mato Grosso. Revista HISTEDBR On-line, Campinas, n.21, p. 44 - 51, mar. 2006.

Recebido em: 05 de março/2019

Aceito em: 14 de julho/2019 